\title{
Learning Management STEAM Model on Massive Open Online Courses Using Augmented Reality to Enhance Creativity and Innovation
}

\author{
Nawarat Wittayakhom ${ }^{1} \&$ Pallop Piriyasurawong ${ }^{1}$ \\ ${ }^{1}$ Division of Information and Communication Technology for Education, Faculty of Technical Education, King \\ Mongkut's University of Technology North Bangkok, Bangkok, Thailand \\ Correspondence: Nawarat Wittayakhom, Division of Information and Communication Technology for Education, \\ Faculty of Technical Education, King Mongkut's University of Technology North Bangkok, Bangkok, Thailand. \\ Tel: 66-863-758-947. E-mail: nawarush23@gmail.com
}

Received: September 5, 2020

doi:10.5539/hes.v10n4p44

\author{
Accepted: October 1, $2020 \quad$ Online Published: October 20, 2020 \\ URL: https://doi.org/10.5539/hes.v10n4p44
}

\begin{abstract}
The purposes of this study were: 1) design Learning Management STEAM Model on Massive Open Online Courses Using Augmented Reality to enhance Creativity and Innovation, 2) suitability assessment of a Learning Management STEAM Model on Massive Open Online Courses Using Augmented Reality to enhance Creativity and Innovation. The research methodology was composed of two parts: the first part involved theories and research papers relating to massive open online courses, augmented reality, elements synthesis, and the design of a Learning Management STEAM Model on Massive Open Online Courses Using Augmented Reality to enhance Creativity and Innovation; the second part involved suitability assessment of this approach. Data were analyzed by using the statistic of the mathematic mean $(\overline{\mathrm{x}})$ and standard deviation (S.D.). The overall result with regard to the suitability of a Learning Management STEAM Model on Massive Open Online Courses Using Augmented Reality to enhance Creativity and Innovation by seven experts was assessed at a very high level, which can be applied to real situations.
\end{abstract}

Keywords: STEAM education, massive open online course, augmented reality, creativity, innovation

\section{Introduction}

Intellectual property is the key factor contributing to national development, so we need to support, encourage and promote the value of intellectual property as a subject of increasing global importance. The key concepts include creative design thinking immersion plan leading to creation of intellectual property across all ages and genders (Uttama, n.d.) idea generation process that leads to innovation such as product, process, and service, values-based recognition, recognition of product quality or service (Shukla, 2009) by using technological advancement and creative thinking for new product development.

Innovation, creativity and information technology play an important role in national development and create competitive potential in business in order to compete in the global economy and digital age. Global innovation index is used for evaluating global ranking of innovation performance and information technology in many countries (Uttama, n.d.). According to rapid development of information and communication technology (ICT) providing new ways of enhancing the teaching and learning process such as educational materials, students are able to seek knowledge from educational resources developed through innovative education technology helping students develop 21st century skills (Techakosit \& Nilsook, 2016). Due to constant development of technology that rapidly changes the way of learning and teaching, it offers students easy access to learning resources. Technology is used to support instructional design and different types of learning and teaching approaches bringing creative ideas and innovative products including knowledge and technology-based new product development and creativity (Uttama, n.d.) as one of the essential skills helping students for the future career.

STEAM is an integrated approach to learning which was evolved from STEM (science, technology, engineering, and mathematics) (Granovskiy, 2018), (IPST, 2016). Studies on the implementation of STEAM elements of education are conducted in many countries: USA, Australia, South Korea, Canada, Thailand, etc (Anisimova et al., 2020). STEAM encourages students to create their own interactive stories, creative design and learns by 
practice helping them develop expertise in problem solving, analysis, synthesis, evaluation, and creation and allowing them to illustrate concepts they are learning and gain a better understanding (Bedar \& Al-Shboul, 2020). STEAM also enables students to develop creative skills and illuminate relationship between critical and creative thinking (Santipaiboon, 2018) which are obvious characteristics found in inventors (Yakman \& Lee, 2012), (Yakman, 2008), (Sriboon, 2018). The use of augmented reality (AR) is to superimpose an image onto users' view of the real world and enhances it with sound (Gulatee \& Nilsook, 2014) to attract and make users experience more immersive. AR helps students become more engaged during classes and support them to learn faster. It also provides teachers with a convenient way to create outdoor learning activities.

The researchers were therefore interested in development of learning management STEAM model on massive open online courses using augmented reality to enhance creativity and innovation. Based on studies, theories, and relevant research paper concerning massive open online courses (MOOC), augmented reality (AR), elements synthesis of learning management STEAM model as a tool for developing skills as well as spending free time on studying with review of learning, this study can be used for further development of learning management towards creative thinking process and a variety of learning process so as to create desired characteristics of students such as knowledge and understanding of contexts in regard to complex thinking skills and creative thinking presentation for innovative products.

\section{Related Literature}

\subsection{STEM Education}

STEAM education is learning management evolved from STEM education and designed to integrate four subjects with each other including science, technology, engineering, and mathematics. Learning management STEAM model promotes innovation and design thinking in students and provides them with means to solve real-world problems according to engineering design process. The following are engineering design process-based teaching and learning model (IPST, 2016): (1) problem identification, (2) related information search, (3) solution design, (4) planning and development, (5) testing, evaluation, and design improvement and (6) presentation. For example, STEM education in Massachusetts uses engineering design process that includes (1) identification of topics and learning objectives, (2) teaching techniques and constraints, (3) various types of instructional design to be used in a way that relevant to context, (4) selection of educational objectives and context and constraints in classrooms, (5) development of learning units, (6) tests, (7) presentation and discussion, (8) improvement after performance evaluation and suggestion (Billiark et al., 2014). Art integration under STEAM concept focuses on innovative design allowing students to work through creative process, experiential learning, real-world work practices, problem-solving, analysis, synthesis, evaluation, and development of creative skills resulting in improving cognitive skills, gaining better understanding what is being taught plus development of creative thinking. Also, STEAM enables students to illuminate relationship between critical and creative thinking, so students can learn science more effectively which is the obvious characteristic found in inventors (Yakman, 2008). STEM has evolved into STEAM which is integration of segmented school subject such as science, technology, engineering, arts, and mathematics with its addition of arts to curriculum to inspire creativity and imagination as well as activities promoting critical thinking skills in science and across all subjects leading to development of creativity (Yakman \& Lee, 2012), (Yakman, 2008), (Sriboon, 2018), (Kim \& Park, 2012), (Wongthong, 2019).

\subsection{Augmented Reality}

Augmented reality (AR) is conceptualized by Tom Caudell and David Mizell while working on Boeing's Computer Services' Adaptive Neural Systems Research and Development Project to help Boeing's manufacturing and engineering process which led them to design software that could overlay the positions of where certain cables in the building process were supposed to go (Kipper, 2013). AR is an immersive computer-based technology that overlays information and virtual objects on real-world scenes in real-time (Eh Phon et al., 2014) and completely absorbs users into a simulated environment. AR is used to enhance all human five senses by adding digital or computer generated information such as images, audio, video and interaction overlaying virtual objects generated in the graphics system (Kalarat, 2015).

Apart from what is mention above, it can be summarized that Augmented Reality is a combination of real and virtual worlds with the use of software systems and connected devices including webcam or other related devices. AR components are as follows: 1) Marker, symbol or designated image used to compare on other images stored in marker database. 2) Video camera, webcam, camera phone or sensor is used for image analysis and image/marker recognition with 3D pose estimation and tracking system. 3) Display - computer monitor or mobile screen or others. 4) Software or processing unit for creating images or 3D objects, the process of turning 
information from a 3D model into a 2D image (3D rendering) where virtual 3D images are merged into real scene (Lim et al., 2017).

There are several ways in which Augmented reality is being used like advertising, games, education (Ahmad \& Junaini, 2020), VR technology in the construction industry or infrastructure with the following methods: (1) augmented reality, (2) 3D modeling, (3) Vuforia SDK, (4) relief mapping (Kalarat, 2015) and (5) AR application in education.

AR application in learning and teaching management should provide students with collaborative learning to help them improve their understanding of lessons and keep them interested in learning. AR can also be applied to other technologies in education, and it makes it possible to give students information at the point of need by offering them virtual reality experience. This naturally leads to collaborative interactions among students and deep understanding of what they are learning (Eh Phon et al., 2014), (Meesuwan, 2011).

In this study, the researchers presented the application of augmented technology to promote graphic creativity since graphics in engineering education involves AR-based (Chen et al., 2011) engineering system architecture composed of five components: (1) tracking and registration module, (2) gesture computing module, (3) operation instruction module, (4) 3D model database and (5) rendering engine working together with mobile augmented reality system for in-situ 3D modeling and authoring that can model 3D virtual objects and author augmented reality contents (Yoo \& Lee, 2014). AR application in education provides new way of learning and teaching. It shapes the learning experience and brings in more experience-based learning which is found to be helpful and interesting. Analysis of augmented reality markers was used for visual mapping and localization and then triggered the display of virtual information in real-time. It brings lessons and textbooks to life by combining video, photos, and audio in an interactive platform. This ultimately provides students with an engaging way to learn that can make complex subjects and topics easier to grasp and understand. Moreover, AR makes teaching easier where teachers no longer need to explain complex concepts.

\subsection{Massive Open Online Course}

Due to advancement in technology, there is a growing trend toward online education. Technology facilitates learning processes and increase performance of the educational system as it regards to effectiveness and/or efficiency. With technology, students can access knowledge at any time and place, review difficult concepts or skip ahead if they need to whereas teachers can transfer their knowledge to students quickly and efficiently. MOOC is blended learning model that is crucial for today's position of higher education. The benefits of MOOC are as follows: (Liqin et al., 2015): 1) MOOC offers effective pedagogy that improves issues associated with academic preparedness and the absence of motivating curriculum. 2) MOOC has been transformed into a more contemporary and attractive learning method where students can access learning materials from world-wide renowned universities and choose from a wide variety of subjects. 3) MOOC assists in educational institutions' teaching and learning management such as digital network, operation, and investigation. 4) There is interaction between students and teachers using MOOC education as well as making up the essence of the collaborative aspects of the MOOC.

Instructional development of MOOC provides a variety of learning components such as (1) videos for explanation, information, sample and experiment, (2) materials, (3) interaction and idea exchange, (4) activities, (5) assessment, and (6) tests. MOOCs for higher education Thailand have five important components as follows:

(1) course management, (2) course instructional design, (3) course development, (4) course implementation, and (5) course evaluation. The dominant learning strategies should be employed in MOOC formats include aggregation, relation, creation and sharing (NSTD, n.d.), (Tinnawas \& Thammetar, 2019).

In this study, components of subjects or lessons design for MOOCs were as follows: (1) short video contents like giving information, example and experiment, (2) exercise and learning materials, (3) interaction and idea exchange, (4) activities, (5) assessment, and (6) tests.

\subsection{Creativity and Innovation}

21 st century skills are essential for educational and learning management system comprising seven skills as well as creativity and innovation. 21st century skills refer to a broad set of knowledge and skills that students need to succeed in careers (Phonok, 2014). According to the concept of Guilfrod (Phanmanee, 1994), creativity was brain that generates diverse ideas or convergent thinking or divergent thinking consisting of fluency, flexibility, originality and elaboration whereas creativity defined by Torrance was integration of experience to produce new combinations of ideas or distinctive products which included three components; fluency, flexibility and originality. For innovation, it can refer to creative thoughts and the process of idea generation that brings new 
products or manufacturing process. Innovation output comprises of knowledge and technology outputs and creative outputs. There are concrete and abstract concepts of innovation. Concrete concept of innovation includes new product/service while abstract concept of innovation refers to new strategies of sales, marketing plan, new process and procedures to improve efficiency or make things faster and easier. In conclusion, creativity is the starting point of innovation whereas innovation refers to the application of ideas and imagination that is novel and useful by using brainstorming techniques to bring different perspectives as well as encompassing improvement of existing production processes or parts of the product. Brainstorming is an encouragement of unconventional ideas with analysis and assessment approaches to develop understanding of creativity (Billiark et al., 2014), (Kim \& Park, 2012), (Panich, 2012), (Chuelooppo et al., 2017).

\section{Objectives of the study}

3.1 Design of Learning Management STEAM Model on Massive Open Online Courses Using Augmented Reality to enhance Creativity and Innovation

3.2 Suitability assessment of Learning Management STEAM Model on Massive Open Online Courses Using Augmented Reality to enhance Creativity and Innovation

\section{Conceptual Framework}

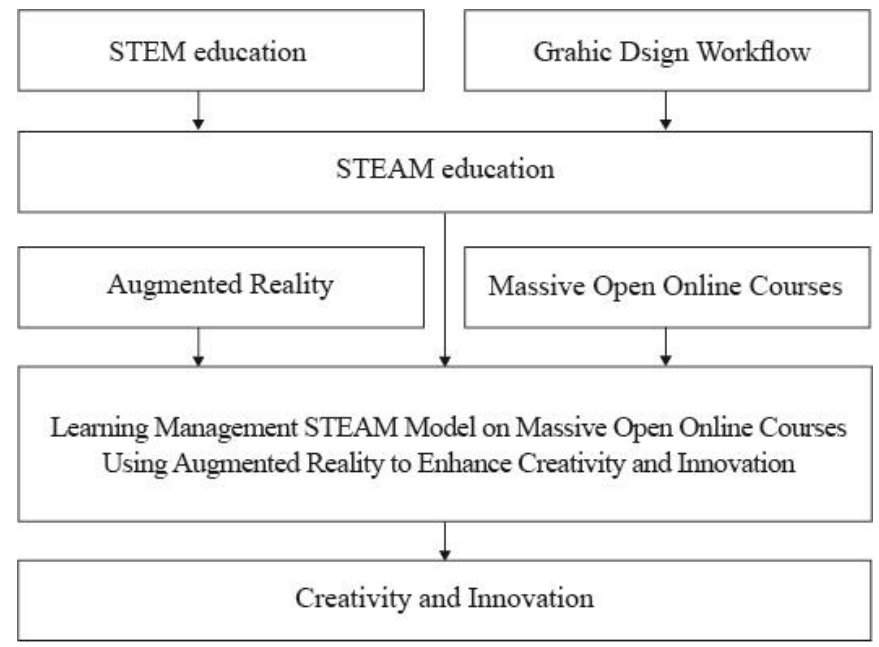

Figure 1. The conceptual framework

Figure 1 shows conceptual framework was composed of three components: 1) input - massive open online courses (edX), STEAM education, augmented reality application, 2) process - learning management STEAM model and system, and 3) output - creativity and innovation. Those were three processes for building learning management STEAM model on massive open online courses using augmented reality to enhance creativity and innovation.

\section{Research Methodology}

The research methods were of 2 phases as follows:

Phase 1: Model Development Study and synthesis of conceptual framework based on concept and principles, analysis, and synthesis of learning management process based on documents and relevant research papers. Details were provided below:

1) Analysis of information gathered from concept and theory relating to online education.

2) Synthesis of STEAM learning process in (Kijkuakul, 2015), (Prasertsang, 2016), (Prasertsang \& Pimkhalee, 2017), (Jantorn, 2017), (IPST, 2016), (Billiark et al., 2014), (ETDA, 2010), (Vasoh, 2015), (Amornchantanakorn, 2015).

3) Analysis of augmented reality concept and theory so as to apply component and technology in learning and teaching management in (Meesuwan, 2015), (Samitritta, 2016), (Yoo \& Lee, 2014), (Gutierrez et al., 2013), (Purnama et al., 2014).

4) Development of Learning Management STEAM Model on Massive Open Online Courses Using Augmented Reality to enhance Creativity and Innovation. 
Phase 2: Suitability Assessment of the Model The process of suitability assessment of Learning Management STEAM Model on Massive Open Online Courses Using Augmented Reality to enhance Creativity and Innovation was as follows:

1) Create instruments for the assessment Learning Management STEAM Model on Massive Open Online Courses Using Augmented Reality to enhance Creativity and Innovation.

2) There are seven experts with Doctorate's degree or not less than five years of teaching experience in higher education. Four experts have a comprehensive knowledge of teaching design and three have a comprehensive knowledge of technology to assess the model.

3) Analyze the assessment data obtained, using the arithmetic mean ( $\bar{x})$ and standard deviation (S.D.).

4) Improve the model as suggested by the experts.

5) Present the designed model.

\section{Results}

6.1 The Developed Model of Learning Management STEAM Model on Massive Open Online Courses Using Augmented Reality to Enhance Creativity and Innovation consisted of 4 components as shown in the figure below

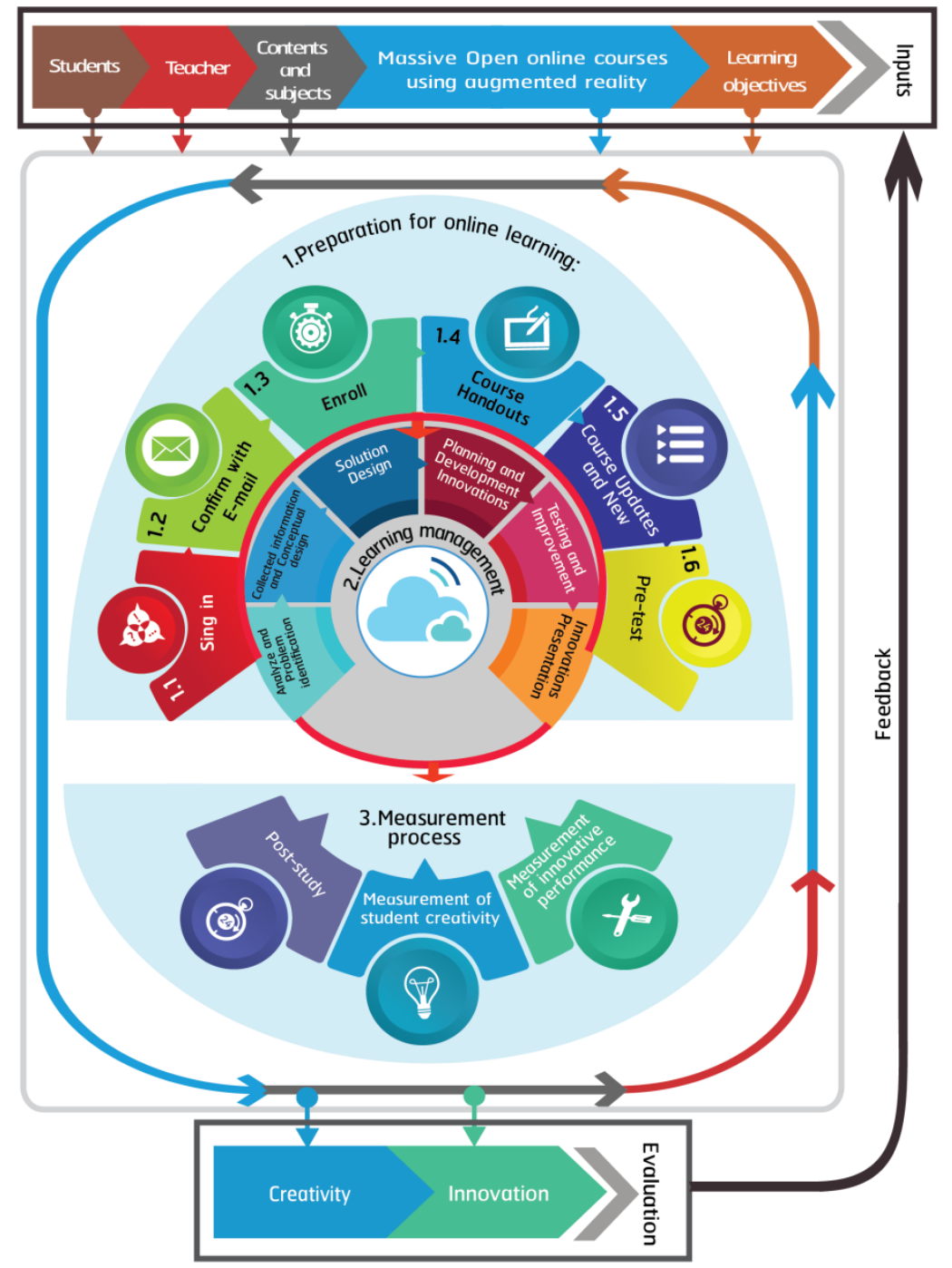

Figure 2. Learning Management STEAM Model onMassive Open Online Courses Using Augmented Reality to Enhance Creativity and Innovation

Figure 2 The process of Learning Management STEAM Model on Massive Open Online Courses Using 
Augmented Reality to enhance Creativity and Innovation as follow:

Analysis of inputs: Studies and analysis of documents and relevant research papers.

Learning objective by setting learning goals or performance goals for student achievement with knowledge and pre-requisite skills.

Contents and subjects for teaching.

Students - analysis of students' learning readiness, learning equipment, and students' interests in creative graphic design for further studies.

Teachers - analysis of students' learning readiness concerning pedagogical content knowledge as well as knowledge and readiness towards learning management system.

The technology of massive open online courses using augmented reality was related to analysis of factors that supported learning and teaching, analysis of educational equipment, activities for practice of knowledge acquisition after each lesson, exercises and tests such as online discussions, use of augmented reality application for enhancing creativity and reviewing previous learning. Moreover, MOOCs supported communication and the exchange of ideas so as to increase collaboration between students and teachers, enhance collaborative learning with a one-way and two-way form of communication including 1) e-mail, a communication channel between students and teachers or among students used for submitting homework assignments, 2) web board - making questions as assigned by teachers that allowed students to have a group discussion and write a summary, 3) chat - a form of communication via application or website between teachers and students, 4) video conference real-time conversation between teachers and students and 5) streaming - broadcasting of live video and sound over the internet.

The process of Learning Management STEAM Model on Massive Open Online Courses Using Augmented Reality to enhance Creativity and Innovation composed of three components:

Preparation for online learning: (1) Signing up for creating an account - students had to provide all needed information to verify their identity, (2) E-mail confirmation and account activation for signing in to account to access to online education, (3) MOOC offered online enrollment according to students' preferred choice of subjects within stipulated timeframe, (4) Course handouts - very useful for explaining important information about learning objectives, course description as well as providing public relations news to students and developers, (5) Course updates and news - concerning explanation of online education process through e-Notice on the system and (6) Pre-test to assess students' prior knowledge.

Learning management STEAM model on massive open online courses using augmented reality was a process that enhanced creativity and innovation and allowed students to view or access the course and its content whereby teachers can create online classes and store course materials, manage assignments/learning activities all in one place e.g. video component, discussion component, contents, augmented reality. The online education system composed of six steps: (1) Analysis and problem identification. (2) Collected information and Conceptual design. (3) Solution design. (4) Planning and development innovations. (5) Testing and Improvement including: (5.1) Experiment for future innovation development. (5.2) Evaluation for future innovation development. (5.3) Improvement for future innovation. (6) Innovation presentation/problem - solving results or results of new product development.

Measurement process included (1) post-study assessment to measure student progress, (2) measurement of student creativity (3) measurement of innovative performance.

Evaluation: the process was as follows:

(1) Evaluation of student creativity after the use of the process of Learning Management STEAM Model on Massive Open Online Courses Using Augmented Reality to enhance Creativity and Innovation with summative evaluation approach and (2) Evaluation of innovative products or ideas after completing the program with summative evaluation approach.

\section{Feedback}

Input of learning reflection through the process of Learning Management STEAM Model on Massive Open Online Courses Using Augmented Reality to enhance Creativity and Innovation for further improvement. 


\subsection{The Result of Model Assessment}

Table 1. The arithmetic mean and standard deviation results from specialists relating to the Learning Management STEAM Model on Massive Open Online Courses Using Augmented Reality to enhance Creativity and Innovation. The five-point Likert scale would be used to determine the weight of assessing the appropriateness of the model

\begin{tabular}{lccc}
\hline \multicolumn{1}{c}{ Description } & \multicolumn{2}{c}{ Result } & Rate of \\
\cline { 2 - 3 } appropriateness \\
\cline { 2 - 3 } 1. Inputs & $\overline{\boldsymbol{x}}$ & S.D. \\
1.1 Learning objectives & & & \\
1.2 Contents and subjects & 5.00 & 0.00 & very high \\
1.3 Students & 5.00 & 0.00 & very high \\
1.4 Teacher & 5.00 & 0.00 & very high \\
1.5 Massive Open online courses using augmented reality & 5.00 & 0.00 & very high \\
2. Learning process & 4.86 & 0.38 & very high \\
2.1 Preparation & & & \\
2.1.1 Sing in & & & \\
2.1.2 Confirm with E-mail & 5.00 & 0.00 & very high \\
2.1.3 Enroll & 5.00 & 0.00 & very high \\
2.1.4 Course Handouts & 5.00 & 0.00 & very high \\
2.1.5 Course Updates and New & 5.00 & 0.00 & very high \\
2.1.6 Pre-test & 5.00 & 0.00 & very high \\
2.2 Online learning & 5.00 & 0.00 & very high \\
2.2.1 Analyze and Problem identification & & & \\
2.2.2 Collected information and Conceptual design & 5.00 & 0.00 & very high \\
2.2.3 Solution Design & 4.57 & 0.53 & very high \\
2.2.4 Planning and Development Innovations & 5.00 & 0.00 & very high \\
2.2.5 Testing and Improvement & 5.00 & 0.00 & very high \\
2.2.6 Innovations Presentation & 4.86 & 0.38 & very high \\
2.3 Measurement process included & 4.86 & 0.38 & very high \\
2.3.1 Post-study assessment to measure student progress & 4.43 & 0.98 & high \\
2.3.2 Measurement of student creativity & 4.57 & 0.79 & very high \\
2.3.3 Measurement of innovative performance & 4.43 & 0.79 & high \\
3. Evaluation & & & \\
3.1 evaluation creativity & 4.71 & 0.49 & very high \\
3 2.evaluation innovative & 4.43 & 0.53 & high \\
4. Feedback & & & \\
4.1 errors checking in each steps & 4.86 & 0.38 & very high \\
Average & 4.85 & 0.24 & very high \\
\hline
\end{tabular}

Table 1 shows the overall result in regard to suitability of Learning Management STEAM Model on Massive Open Online Courses Using Augmented Reality to enhance Creativity and Innovation assessed by those experts was at the very high level with the mean and standard deviation $(\bar{x}=4.85$, S.D. $=0.24)$.

\section{Discussion}

The Learning Management STEAM Model on Massive Open Online Courses Using Augmented Reality to enhance Creativity and Innovation is the learning management that applies augmented reality to the STEAM education process, and to act in the real world, leading to the enhancement of creativity and innovation. Seven specialists in this field agree that the developed learning-management model was at the most appropriate level. Our results relate to the work of Techakosit and Nilsook (2016) who employ the Learning Process of Scientific Imagineering in their research and found that AR can enhance STEM literacy, as published in an article entitled 'The Learning Process of Scientific Imagineering through AR in Order to Enhance STEM Literacy'. In addition, our results are also consistent with those from the research paper of Chuelooppo, Bongkotphet, and Warangkanagool (2017), entitled "Developing 10th Grade Students' Creativity Using Stem Approach Based on Engineering Design Process in the Topic of Rotational Motion". Both our findings and the results from the literature suggest that learning management with an emphasis on engineering design according to STEAM 
education can develop student creativity ranking from the highest to the lowest included flexibility, originality, elaboration, and fluency.

\section{Conclusions}

The study concluded that fluency, flexibility, originality, and elaboration are components applied to learn management STEAM model on massive open online courses using augmented reality to enhance creativity. The process of synthesis of Learning Management STEAM Model on Massive Open Online Courses Using Augmented Reality to enhance Creativity and Innovation followed:

1. Online learning preparation included signing up, e-mail confirmation, MOOC enrollment, course handouts, course updates and news, and pre-assessment.

2. Online learning classes created by teachers through social media learning based system consisted of six steps: (1) analysis and problem identification, (2) conceptual design), (3) solution design), (4) planning and development innovations), (5) testing and improvement including (5.1) experiment for future innovation development, (5.2) evaluation for future innovation development, (5.3) improvement for future innovation and (6) Innovation presentation/problem-solving results or results of new product development.

3. Measurement process included (1) post-study assessment to measure student progress, (2) measurement of student creativity, and (3) measurement of innovation relating to the measurement of student innovative performance.

\section{Acknowledgment}

This research received a partial thesis research grant for graduate students from the Graduate College at King Mongkut's University of Technology North Bangkok, Bangkok, Thailand

\section{References}

Ahmad, N. I. N., \& Junaini, S. N. (2020). Augmented reality for learning mathematics. International Journal of Emerging Technologies in Learning, 15(16), 106-122. https://doi.org/10.3991/ijet.v15i16.14961

Amornchantanakorn, U. (2015). Graphic Design Basic. Retrieved from http://slideplayer.in.th/slide/2226936

Anisimova, T. I., Sabirova, F. M., \& Shatunova, O. V. (2020). Formation of design and research competencies in future teachers in the framework of STEAM education. International Journal of Emerging Technologies in Learning, 15(2), 204-217. https://doi.org/10.3991/ijet.v15i02.11537

Bedar, R. W. A.-H., \& Al-Shboul, M. A. (2020). The Effect of Using STEAM Approach on Motivation Towards Learning Among High School Students in Jordan. International Education Studies, 13(9), 48. https://doi.org/10.5539/ies.v13n9p48

Billiark, K., Hubelbank, J., Oliva, T., \& Camesano, T. (2014). Teaching STEM by design. Advances in Engineering Education, 4(1), 1-21.

Chen, H., Feng, K., Mo, C., Cheng, S., Guo, Z., \& Huang, Y. (2011). Application of augmented reality in engineering graphics education. ITME 2011 - Proceedings: 2011 IEEE International Symposium on IT in Medicine and Education, 2, 362-365. https://doi.org/10.1109/ITiME.2011.6132125

Chuelooppo, S., Bongkotphet, T., \& Warangkanagool, C. (2017). Developing 10 th Grade Students ' Creativity Using Stem Approach Based on Engineering Design Process in the Topic of Rotational Motion. The 17th Graduate Studies of Northern Rajabhat University Network Conference, pp. 139-152.

Electronic Transactions Development Agency (Public Organization). (2010). Design guide. Retrieved from https://goo.gl/wHBynN

Eh Phon, D. N., Ali, M. B., \& Halim, N. D. A. (2014). Collaborative augmented reality in education: A review. Proceedings - 2014 International Conference on Teaching and Learning in Computing and Engineering, LATICE 2014, pp. 78-83. https://doi.org/10.1109/LaTiCE.2014.23

Granovskiy, B. (2018). Science, Technology, Engineering, and Mathematics (STEM) Education: An Overview. Congressional Research Service, 1-29.

Gulatee, Y., \& Nilsook, P. (2014). Elements of Learning Design for MOOCs. The Fifth TCU International E-Learning Conference, August. https://doi.org/10.13140/2.1.3914.4321

Gutierrez, F., Abud, M. A., Vera, F., \& Sanchez, J. A. (2013). Application of contextual QR codes to augmented reality technologies. 23rd International Conference on Electronics, Communications and Computing, CONIELECOMP 2013, pp. 264-269. https://doi.org/10.1109/CONIELECOMP.2013.6525798 
Institute for the Promotion of Teaching Science and Technology. (2016). Design of stem educational activities. Retrieved from https://bit.ly/31m3yDz

Jantorn, P. (2017). Process "Stem Activity". Retrieved from https://bit.ly/2z0QGY3

Kalarat, K. (2015). Applying Relief Mapping on Augmented Reality. Proceedings of the 2015 12th International Joint Conference on Computer Science and Software Engineering, JCSSE 2015, pp. 315-318. https://doi.org/10.1109/JCSSE.2015.7219816

Kijkuakul, S. (2015). Stem Education. Journal of Education Naresuan University, 17(2), 201-207. https://doi.org/10.1038/scientificamerican0217-5

Kim, Y., \& Park, N. (2012). The effect of STEAM education on elementary school Student's Creativity Improvement * Mechanical Mechanism of Rube Goldberg Machine Contest. Computer Applications for Security, Control and System Engineering, pp. 115-121. https://doi.org/10.1007/978-3-642-35264-5_16

Kipper, G. (2013). What Is Augmented Reality?. Augmented Reality, 1-27. https://doi.org/10.1016/b978-1-59-749733-6.00001-2

Lim, C., Kim, C., Park, J. I., \& Park, H. (2017). Mobile Augmented Reality Based on Invisible Marker. Adjunct Proceedings of the 2016 IEEE International Symposium on Mixed and Augmented Reality, ISMAR-Adjunct 2016, pp. 78-81. https://doi.org/10.1109/ISMAR-Adjunct.2016.0045

Liqin, Z., Ning, W., \& Chunhui, W. (2015). Construction of a MOOC based blend learning mode. 10th International Conference on Computer Science and Education, ICCSE 2015, Iccse, pp. 997-1000. https://doi.org/10.1109/ICCSE.2015.7250397

Meesuwan, W. (2011). AUGMENTED REALITY TECHNOLOGY FOR LEARNING. Journal of Education Naresuan University, 13(2), 119-127.

Panich, V. (2012). Ways to create learning for students in the 21st century. Bangkok: Sodsri-Saridwongso Foundation.

Phanmanee, A. (1994). Creativity. Bangkok: Tonaor Grammy.

Phonok, J. (2014). 21st century skills. Retrieved from https://bit.ly/2xxiD9q

Prasertsang, P. (2016). Learning Design for STEM Education. Prae-WaKalasin Journal of Kalasin University, $3(3), 129-140$.

Prasertsang, P., \& Pimkhalee, N. (2017). Development of Learning Activities Using STEM Education in Mathematics for Third Grade Students. Journal of Education, Mahasarakham University, 11(1), 132-143.

Purnama, J., Andrew, D., \& Galinium, M. (2014). Geometry learning tool for elementary school using augmented reality. Proceedings - International Conference on Industrial Automation, Information and Communications Technology, IAICT 2014, August, pp. 145-148.

https://doi.org/10.1109/IAICT.2014.6922112

Santipaiboon, J. (2018). Learner's development activities by steam and productivity based learning to enhance the process skills and creative abilities in third grade students. A Thesis Submitted in Partial Fulfillment of the Requirements for Master of Education. NakhonPathom: Silpakorn University

Shukla, A. (2009). What is Innovation? Why Innovation is important?. Retrieved from https://www.paggu.com/getting-into-roots\%20/what-is-innovation-why-innovation-is-important

Sriboon, S. (2018). The learning outcome of steam education based on problem based learning to developing mathematical skills and process for seventh grade students. A Thesis Submitted in Partial Fulfillment of the Requirements for Master of Education. Nakhon Pathom: Silpakorn University.

Techakosit, S., \& Nilsook, P. (2016). The learning process of scientific imagineering through AR in order to enhance STEM literacy. International Journal of Emerging Technologies in Learning, 11(7), 57-63. https://doi.org/10.3991/ijet.v11i07.5357

The institute for the Promotion of Teaching Science and Technology. (2016). STEM Education Thailand. Retrieved from http://www.stemedthailand.org

Tinnawas, N., \& Thammetar, T. (2019). The Study Of Massive Open Online Course Model For Thai Higher Education. Veridian E-Journal, Silpakorn University, 9(3), 1463-1479.

Uttama, N. (n.d.). Innovation, creativity and information technology: unlocking the key to national growth. 
Retrieved from http://rs.mfu.ac.th/obels/?p=1335

Vasoh, A. (2015). Graphic Design for Printing \& Publishing. Nonthaburi: IDC Premier Co., Ltd.

Wongthong, P. (2019). Effect of Integrated Learning Activities Based on STEAM Education on Science Learning Achievement, Critical Thinking Skills and Students ' Satisfaction of Grade 4 Students. Journal of Research Unit on Science, Technology and Environment for Learning, 10(1), 94-112.

Yakman, G. \& Lee, H. (2012). Exploring the Exemplary STEAM Education in the U.S. as a Practical Educational Framework for Korea. Journal of The Korean Association For Science Education, 32(6), 1072-1086. https://doi.org/10.14697/jkase.2012.32.6.1072

Yakman, G. (2008). ST $\sum @ M$ Education: an overview of creating a model of integrative education. PATT-17 and PATT-19 Proceedings, February 2008, pp. 335-358. https://www.iteea.org/File.aspx?id=86752\&v=75ab076a

Yoo, H. K., \& Lee, J. W. (2014). Mobile augmented reality system for in-situ 3D modeling and authoring. In 2014 International Conference on Big Data and Smart Computing, BIGCOMP 2014, pp. 282-285. https://doi.org/10.1109/BIGCOMP.2014.6741453

\section{Copyrights}

Copyright for this article is retained by the author(s), with first publication rights granted to the journal.

This is an open-access article distributed under the terms and conditions of the Creative Commons Attribution license (http://creativecommons.org/licenses/by/4.0/). 